\title{
Association between Abdominal Obesity and Cardiovascular Risk Factors in Adults with Normal Body Mass Index: Based on the Sixth Korea National Health and Nutrition Examination Survey
}

\author{
Hye Yun Kim', Jae Kyung Kim', Gook Gyeon Shin', Jin Ah Han', Jin Wook Kim ${ }^{1,2, *}$ \\ ${ }^{1}$ Department of Family Medicine, Obesity and Metabolic Disease Center, Seongnam Central Hospital, Seongnam; ${ }^{2}$ Department of Family Medicine, Korea University \\ College of Medicine, Seoul, Korea
}

\begin{abstract}
Background: Abdominal obesity predisposes individuals to cardiovascular disease, but the data in adults with normal body mass index (BMI) are relatively rare. This study aimed to evaluate the characteristics of subjects with normal BMI and abdominal obesity and to identify the relationship between central obesity and cardiovascular risk factors in normal BMl adults in Korea.

Methods: Ten thousands six hundred thirty-four adults with BMl between 18.5 to $24.9 \mathrm{~kg} / \mathrm{m}^{2}$ who participated in the sixth Korea National Health and Nutrition Examination Survey were included. Abdominal obesity was defined as a waist circumference of $\geq 90 \mathrm{~cm}$ in males and $\geq 85 \mathrm{~cm}$ in females. Through logistic regression, we analyzed the factors influencing abdominal obesity and the relationship between abdominal obesity and cardiovascular risk factors.

Results: The prevalence of abdominal obesity in adults with normal BMI was $6.9 \%$ for males and $7.7 \%$ for females, and this prevalence tended to increase with age. When adjusted for age and BMI, daily excessive alcohol consumption increased the risk of abdominal obesity in adults of normal weight. Women with lower socioeconomic status and men in need of walking exercise also had a higher risk of abdominal obesity. In the model adjusted for age and BMI, abdominal obesity was associated with fasting glucose intolerance and diabetes in men and hypertriglyceridemia and low high-density lipoprotein cholesterol in women.

Conclusion: Cardiovascular risk factors were associated with abdominal obesity in Korean adults with normal $\mathrm{BMI}$. These results suggest that more careful management of abdominal obesity in those with normal weight is necessary.
\end{abstract}

Key words: Normal body weight, Abdominal obesity, Cardiovascular disease risk factors

\author{
Received June 28, 2019 \\ Reviewed August 7, 2019 \\ Accepted October 25, 2019 \\ *Corresponding author \\ Jin Wook Kim \\ (iD) \\ https://orcid.org/0000-0001-9584-0974 \\ Department of Family Medicine, \\ Obesity and Metabolic Disease Center, \\ Seongnam Central Hospital, \\ 12 Sanseong-daero 476beon-gil, \\ Jungwon-gu, Seongnam 13161, Korea \\ Tel: +82-31-799-5541 \\ Fax: +82-31-744-8994 \\ E-mail: julybook@korea.ac.kr
}

\section{INTRODUCTION}

Obesity is defined as a state of abnormal or excessive accumulation of adipose tissue that leads to health risks. Body mass index (BMI) was used to define the criteria for obesity. ${ }^{1}$ However, studies have reported that BMI may not accurately predict actual fat mass if the value is below $30.0 \mathrm{~kg} / \mathrm{m}^{2}{ }^{2}$ Moreover, recent studies have shown that abdominal obesity, rather than obesity simply defined by BMI, is more highly correlated with cardiovascular and metabolic diseases. According to studies in the United States and Canada, individuals with normal BMI and abdominal obesity showed higher risks of cardiovascular diseases compared to individuals classi-

Copyright (C) 2019 Korean Society for the Study of Obesity

(a) This is an Open Access article distributed under the terms of the Creative Commons Attribution Non-Commercial License (http://creativecommons.org/licenses/by-nc/4.0/) which permits unrestricted non-commercial use, distribution, and reproduction in any medium, provided the original work is properly cited. 
fied as obese according to BMI without abdominal obesity.-6 Mortality from coronary artery disease was also found to be higher in individuals with normal BMI and abdominal obesity. ${ }^{7,8}$ Although quantifying visceral and subcutaneous fat by computed tomography (CT) is the most accurate diagnostic method for abdominal obesity, CT use is limited because of high cost and risk of radiation exposure. Because waist circumference is highly correlated with visceral fat and is easy to measure and interpret, this is used as the basic clinical tool for evaluating abdominal obesity. ${ }^{9}$ Asians are known to have more severe abdominal obesity than Caucasians with identical BMIs leading to the suggestion that different diagnostic criteria should be applied to different races. In 2009, the American Heart Association/ National Heart, Lung, and Blood Institute and International Association for the Study of Obesity defined abdominal obesity in Asians as a waist circumference of $\geq 90 \mathrm{~cm}$ for males and $\geq 80 \mathrm{~cm}$ for females. ${ }^{10}$ Currently in South Korea, slightly different criteria, waist circumference of $\geq 90 \mathrm{~cm}$ for males and $\geq 85 \mathrm{~cm}$ for females, have been suggested by the Korean Society for the Study of Obesity based on the Korea National Health and Nutrition Examination Survey (KNHANES) data from 1998. ${ }^{11}$

Individuals classified as having a normal body weight based on BMI despite the presence of abdominal obesity are often not recognized as obese in the primary care setting and may not acknowledge their obesity. As a result, these individuals may not receive management for abdominal obesity or participate in programs to prevent future cardiovascular or metabolic diseases. ${ }^{12}$ In a study conducted in 9,447 individuals in Jilin Province of China, 55.6\% of individuals with normal body weight and abdominal obesity did not acknowledge their obesity, and only $12.7 \%$ were attempting to lose weight. ${ }^{13}$ Therefore, we should pay more attention to the individual with abdominal obesity and normal body weight.

Few studies have examined abdominal obesity in adults with normal body weight in South Korea. According to a South Korean study based on the KNHANES of 2009-2010, 32\% of adults with normal BMI were found to have body fat percentages that were greater than or equal to obesity cutoffs when measured by dual energy X-ray absorptiometry. Individuals who were abdominally obese with normal body weight showed an increased prevalence of cardiovascular diseases. ${ }^{14}$ A 2001 study on 678 adults who sought health examinations and who had a BMI less than $23.0 \mathrm{~kg} / \mathrm{m}^{2}$, de- termined that a higher body fat percentage measured by bioelectrical impedance analysis was associated with higher risks of cardiovascular diseases, especially in males. ${ }^{15}$ Although these studies increased the interest in obesity with normal body weight in South Korea, the influence of fat distribution was not clearly determined. A previous study showed that visceral adiposity measured by dual energy X-ray absorptiometry was associated with triglycerides in 156 adults with normal body weight who participated in the 2011 KNHANES.$^{16}$ However, the study had a small sample size and no further studies have been conducted using more recent South Korean data. Therefore, this study was conducted to identify the factors that increase the risks of abdominal obesity in Korean adults with normal body weight and to investigate the relationship between abdominal obesity and cardiovascular risk factors, such as hypertension, diabetes, and dyslipidemia, based on the sixth KNHANES (2013-2015).

\section{METHODS}

\section{Participants}

Among adults aged 19 years or more who participated in the sixth KNHANES (2013-2015), data from 10,634 (4,336 males and 6,298 females) individuals with BMI between 18.5 and $24.9 \mathrm{~kg} / \mathrm{m}^{2}$ were analyzed.

\section{Ethics statement and data access}

This study used the database from the sixth KNHANES (20132015). Access to the KNHANES data was acquired after receiving approval by the Institutional Review Board (IRB) of the Korea Centers for Disease Control and Prevention (2013-07CON-034C, 2013-12EXP-03-5C). This study was a cross-sectional study that used and analyzed the data from the sixth KNHANES survey. The dataset did not include personal information and participants gave consent to the KNHANES. Therefore, further ethical approval for the use of open KNHANES data was exempted by the IRB.

\section{Clinical variables}

Among the items assessed in the KNHANES, health questionnaire and physical exam data were used. An individual was considered to be normal weight if the BMI was 18.5 to $24.9 \mathrm{~kg} / \mathrm{m}^{2}$ ac- 
cording to the classification established by the World Health Organization. ${ }^{1}$ Abdominal obesity was defined as a waist circumference of $\geq 90 \mathrm{~cm}$ in males and $\geq 85 \mathrm{~cm}$ in females in accordance with the criteria suggested by the Korean Society for the Study of Obesity. The mean age was calculated for each group classified based on sex and abdominal obesity, and age in years was categorized as 19-44, $45-64$, and 65 years or older.

For sociodemographic indices, variables included the area of residence (region), family income, and education level attained. For area of residence, the subject's address was used to classify those living in "dong" as urban residents and those living in "eup" or "myeon" as rural residents. Family income was classified into four groups based on an equalized average monthly income; and education level was also classified into four groups: elementary school graduation or lower, middle school graduation, high school graduation, and college graduation or higher. For health-related behaviors, smoking, excessive alcohol consumption frequency, and walking exercise frequency were analyzed. Smoking was classified into lifetime non-smoker, ex-smoker, and current smoker. Harmful alcohol consumption was analyzed as a weekly frequency and defined as seven standardized glasses or more per drinking event for males and five standardized glasses or more for females in accordance with KNHANES criteria. Frequency of walking exercise was categorized as 0-2, 3-5, and 6-7 days per week.

Risk factors for cardiovascular diseases were defined as described below. Systolic blood pressure of 120-140 mmHg or diastolic blood pressure of $80-90 \mathrm{mmHg}$ was defined as pre-hypertension. A systolic blood pressure of $\geq 140 \mathrm{mmHg}$, diastolic blood pressure of $\geq 90 \mathrm{mmHg}$, or administration of antihypertensive medications was defined as having hypertension. Fasting glucose levels of 100 $125 \mathrm{mg} / \mathrm{dL}$ was defined as impaired fasting glucose; and fasting glucose levels of $\geq 126 \mathrm{mg} / \mathrm{dL}$, doctor's diagnosis of diabetes, or administration of anti-hypoglycemic agents or insulin was defined as having diabetes. Dyslipidemia was classified into hypercholesterolemia when the total cholesterol level was $\geq 240 \mathrm{mg} / \mathrm{dL}$ or when individuals were being administered cholesterol medications, hypertriglyceridemia when triglyceride was $200 \mathrm{mg} / \mathrm{dL}$ or higher upon fasting for $\geq 12$ hours, and hypo-high-density lipoprotein (HDL) cholesterolemia when HDL was $<40 \mathrm{mg} / \mathrm{dL}$ after $\geq 8$ hours of fasting.

\section{Data analysis}

The complex sample analysis was conducted for the KNHANES data for weighing all values. For each variable, missing values were treat as valid. The prevalence of cardiovascular risk factors was analyzed according to the general characteristics and waist circumference of the participants by chi-square tests and t-tests. Variables showing significant differences between the normal waist circumference and abdominal obesity groups were further analyzed by logistic regression analysis. Moreover, the relative risks of cardiovascular risk factors according to abdominal obesity were analyzed by logistic regression analysis. All values were considered significant when the $P$-value was $<0.05$ for the $95 \%$ confidence interval (CI). Analyses were conducted using IBM SPSS version 22.0 (IBM Corp., Armonk, NY, USA).

\section{RESULTS}

\section{Differences in general characteristics in adults with} normal body weight according to the presence of abdominal obesity

Participants with normal BMI were classified into the normal waist circumference and abdominal obesity groups; their general characteristics are shown in Table 1. The prevalence of abdominal obesity in adults with normal body weight was $6.9 \%$ in males and $7.7 \%$ in females. This difference was significantly higher in females $(P=0.020)$. The mean BMI in the group without abdominal obesity was $22.34 \pm 1.64 \mathrm{~kg} / \mathrm{m}^{2}$ in males and $21.86 \pm 1.69 \mathrm{~kg} / \mathrm{m}^{2}$ in females. The mean BMI in the group with abdominal obesity was $24.1 \pm 0.81 \mathrm{~kg} / \mathrm{m}^{2}$ in males and $23.79 \pm 0.69 \mathrm{~kg} / \mathrm{m}^{2}$ in females; thus, the mean BMI was significantly higher in the group with abdominal obesity than in the control group without abdominal obesity $(P<0.001)$. For both males and females, the mean age was higher in the groups with abdominal obesity, and the prevalence of abdominal obesity tended to increase with increased age $(P<0.001)$.

In both men and women with normal BMI and abdominal obesity, family income, education levels, and walking exercise frequency were lower and excessive alcohol consumption frequency was higher than the control group. Moreover, the abdominal obesity group and control group showed significant differences in smoking history in men $(P=0.022)$ and area of residence in women $(P=0.047)$. 
Table 1. Differences in general characteristics according to the presence of abdominal obesity in adults with normal BMl

\begin{tabular}{|c|c|c|c|c|c|c|}
\hline \multirow[b]{2}{*}{ Variable } & \multicolumn{3}{|c|}{ Male $(n=4,336)$} & \multicolumn{3}{|c|}{ Female $(n=6,298)$} \\
\hline & $\begin{array}{c}W C<90 \mathrm{~cm} \\
(n=4,036,93.1 \%)\end{array}$ & $\begin{array}{c}W C \geq 90 \mathrm{~cm} \\
(\mathrm{n}=300,6.9 \%)\end{array}$ & $P$ & $\begin{array}{c}W C<85 \mathrm{~cm} \\
(\mathrm{n}=5,809,92.3 \%)\end{array}$ & $\begin{array}{c}W C \geq 85 \mathrm{~cm} \\
(\mathrm{n}=489,7.7 \%)\end{array}$ & $P$ \\
\hline WC (cm) & $80.19 \pm 5.45$ & $92.43 \pm 42.39$ & & $74.33 \pm 5.59$ & $87.99 \pm 2.62$ & \\
\hline $\mathrm{BMI}\left(\mathrm{kg} / \mathrm{m}^{2}\right)$ & $22.34 \pm 1.64$ & $24.1 \pm 0.81$ & $<0.001$ & $21.86 \pm 1.69$ & $23.79 \pm 0.69$ & $<0.001$ \\
\hline Age (yr) & $50.80 \pm 17.28$ & $63.27 \pm 12.63$ & $<0.001$ & $48.90 \pm 16.25$ & $63.831 \pm 4.48$ & $<0.001$ \\
\hline Age group (yr) & & & $<0.001$ & & & $<0.001$ \\
\hline $19-44$ & $1,553(50.6)$ & $29(15.3)$ & & $2,464(50.6)$ & $63(20.4)$ & \\
\hline $45-64$ & 1,422 (35.9) & $115(49.1)$ & & $2,205(36.1)$ & $142(29.8)$ & \\
\hline$\geq 65 \mathrm{yr}$ & 1,061 (13.5) & $156(35.6)$ & & $1,140(13.4)$ & $284(49.8)$ & \\
\hline Region & & & 0.603 & & & 0.047 \\
\hline Urban & $3,210(81.9)$ & 234 (80.5) & & $4,813(84.6)$ & 377 (80.2) & \\
\hline Rural & $826(18.1)$ & $66(19.5)$ & & $996(15.4)$ & 112 (19.8) & \\
\hline Family income & & & 0.010 & & & $<0.001$ \\
\hline Lowest & $733(13.6)$ & $85(21.3)$ & & $1,005(14.5)$ & 192 (34.8) & \\
\hline Low-middle & $1,019(24.9)$ & $75(26.3)$ & & $1,390(23.6)$ & $134(28.1)$ & \\
\hline Middle-high & 1,083 (29.7) & $76(26.7)$ & & 1,597 (29.3) & $88(21.0)$ & \\
\hline High & 1,172 (31.8) & $61(25.8)$ & & 1,777 (32.5) & $70(16.1)$ & \\
\hline Education & & & $<0.001$ & & & $<0.001$ \\
\hline$\leq$ Elementary school & $615(11.2)$ & $75(22.2)$ & & $1,172(16.3)$ & $262(51.4)$ & \\
\hline Middle school & $405(8.9)$ & $38(13.6)$ & & $501(8.1)$ & $55(13.3)$ & \\
\hline High school & $1,345(41.7)$ & 82 (33.4) & & 1,851 (37.8) & $87(23.4)$ & \\
\hline$\geq$ College & 1,248 (38.2) & $68(30.8)$ & & 1,823 (37.8) & $40(11.8)$ & \\
\hline Smoking & & & 0.022 & & & 0.999 \\
\hline Never & $863(25.7)$ & $48(19.0)$ & & 4,958 (89.0) & $400(89.0)$ & \\
\hline Ex-smoker & 1,461 (33.8) & 134 (43.5) & & $277(5.6)$ & $21(5.6)$ & \\
\hline Current smoker & $1,411(40.6)$ & $96(37.5)$ & & $272(5.5)$ & $21(5.4)$ & \\
\hline Binge drinking & & & $<0.001$ & & & 0.020 \\
\hline Never & 726 (20.5) & $55(21.5)$ & & 1,696 (44.2) & $116(49.4)$ & \\
\hline$\leq$ Once a week & 2,088 (70.9) & $122(58.2)$ & & $1,820(53.7)$ & $85(45.3)$ & \\
\hline Nearly daily & $269(8.6)$ & $38(20.3)$ & & $66(2.1)$ & $8(5.3)$ & \\
\hline Walking exercise (day/wk) & & & $<0.001$ & & & 0.002 \\
\hline $0-2$ & $1,164(31.0)$ & $111(47.1)$ & & $1,800(32.3)$ & $188(41.8)$ & \\
\hline $3-5$ & $1,030(28.2)$ & $72(26.1)$ & & $1,807(34.2)$ & 132 (28.2) & \\
\hline $6-7$ & $1,412(40.7)$ & $80(26.8)$ & & $1,735(33.5)$ & $123(30.0)$ & \\
\hline
\end{tabular}

Values are presented as mean \pm standard deviation or number (\%).

$\mathrm{BMI}$, body mass index; WC, waist circumference.

Association between sociodemographic indices, healthrelated behavior, and abdominal obesity in adults with normal body weight

Table 2 shows the results of logistic regression analysis conducted to investigate the association between sociodemographic indices, health-related behaviors, and abdominal obesity in adults with normal body weight. The odds ratio for abdominal obesity based on age was 1.055 (95\% CI, 1.046-1.064) for males and 1.058 (95\% CI, 1.048-1.068) for females. The results remained significant after adjusting for BMI (male: 1.066 [95\% CI, 1.055-1.077]; female: 1.051 [95\% CI, 1.039-1.062]).

When adjusted for age and BMI, the odds ratio was 2.426 (95\% CI, 1.319-4.464) in males who consumed alcohol excessively every day and 1.810 (95\% CI, 1.218-2.688) in males who performed walking exercise 2 or fewer days per week. Although the odds ratios were decreased in this model compared to the unadjusted model, the results remained significant. In females, the odds ratio was 4.366 (95\% CI, 1.637-11.640) for participants who consumed al- 
Table 2. Unadjusted and adjusted odds ratio of abdominal obesity in relation to sociodemographic factors and health-related behavior in adults with normal BMI

\begin{tabular}{|c|c|c|c|c|c|c|c|c|}
\hline \multirow{3}{*}{ Variable } & \multicolumn{4}{|c|}{ Male } & \multicolumn{4}{|c|}{ Female } \\
\hline & \multicolumn{2}{|l|}{ Unadjusted } & \multicolumn{2}{|c|}{ Age and BMl adjusted } & \multicolumn{2}{|l|}{ Unadjusted } & \multicolumn{2}{|c|}{ Age and BMl adjusted } \\
\hline & OR (95\% Cl) & $P$ & OR $(95 \%$ Cl) & $P$ & OR (95\% Cl) & $P$ & OR (95\% Cl) & $P$ \\
\hline Age & $1.055(1.046-1.064)$ & $<0.001$ & & & $1.058(1.048-1.068)$ & $<0.001$ & & \\
\hline $\mathrm{BMl}$ & $1.814(1.671-1.969)$ & $<0.001$ & & & $1.626(1.553-1.704)$ & $<0.001$ & & \\
\hline \multicolumn{9}{|l|}{ Region } \\
\hline Urban & 1 & & 1 & & 1 & & 1 & \\
\hline Rural & 1.095 (0.777-1.542) & 0.603 & 1.213 (0.808-1.820) & 0.351 & $1.355(1.003-1.831)$ & 0.048 & $0.883(0.635-1.227)$ & 0.458 \\
\hline Family income & & 0.002 & & 0.547 & & $<0.001$ & & $<0.001$ \\
\hline Lowest & $1.928(1.330-2.795)$ & 0.001 & 0.907 (0.589-1.397) & 0.658 & $4.830(3.482-6.701)$ & $<0.001$ & $2.100(1.430-3.082)$ & $<0.001$ \\
\hline Low-middle & 1.301 (0.877-1.930) & 0.191 & $1.175(0.753-1.832)$ & 0.478 & $2.398(1.701-3.382)$ & $<0.001$ & $1.877(1.305-2.700)$ & 0.001 \\
\hline Middle-high & 1.105 (0.724-1.688) & 0.643 & 1.214 (0.773-1.906) & 0.400 & 1.445 (0.999-2.092) & 0.051 & 1.332 (0.905-1.961) & 0.146 \\
\hline High & 1 & & 1 & & 1 & & 1 & \\
\hline Education & & $<0.001$ & & 0.739 & & $<0.001$ & & 0.001 \\
\hline$\leq$ Elementary school & $2.468(1.657-3.675)$ & $<0.001$ & $0.810(0.510-1.289)$ & 0.374 & $10.083(6.612-15.375)$ & $<0.001$ & $2.345(1.395-3.942)$ & 0.001 \\
\hline Middle school & $1.904(1.172-3.094)$ & $<0.001$ & 0.868 (0.507-1.487) & 0.606 & 5.222 (3.111-8.768) & $<0.001$ & $1.795(1.021-3.157)$ & 0.042 \\
\hline High school & 0.993 (0.667-1.478) & 0.973 & 1.012 (0.660-1.551) & 0.957 & $1.977(1.243-3.144)$ & 0.004 & $1.176(0.719-1.924)$ & 0.518 \\
\hline$\geq$ College & 1 & & 1 & & 1 & & 1 & \\
\hline Binge drinking & & $<0.001$ & & 0.011 & & 0.033 & & 0.009 \\
\hline Never & 1 & & 1 & & 1 & & 1 & \\
\hline$\leq$ Once a week & 0.782 (0.530-1.153) & 0.214 & 1.229 (0.776-1.946) & 0.379 & $0.757(0.541-1.057)$ & 0.071 & 1.295 (0.896-1.873) & 0.169 \\
\hline Nearly daily & $2.245(1.363-3.700)$ & 0.002 & $2.426(1.319-4.464)$ & 0.004 & $2.317(0.931-5.763)$ & 0.102 & $4.366(1.637-11.640)$ & 0.003 \\
\hline Smoking & & 0.020 & & 0.182 & & 0.999 & & 0.165 \\
\hline Never & 1 & & 1 & & $0.999(0.601-1.659)$ & 0.996 & $1.629(0.897-2.957)$ & 0.309 \\
\hline Ex-smoker & $1.746(1.150-2.651)$ & 0.009 & 0.948 (0.598-1.503) & 0.234 & $0.986(0.566-1.720)$ & 0.962 & $1.418(0.723-2.779)$ & 0.109 \\
\hline Current-smoker & 1.253 (0.808-1.944) & 0.313 & $1.359(0.820-2.253)$ & 0.069 & 1 & & 1 & \\
\hline Walking exercise (day/wk) & & $<0.001$ & & 0.012 & & 0.001 & & 0.248 \\
\hline $0-2$ & $2.305(1.600-3.323)$ & $<0.001$ & $1.810(1.218-2.688)$ & 0.003 & $1.441(1.090-1.906)$ & 0.010 & 1.163 (0.854-1.583) & 0.822 \\
\hline $3-5$ & 1.403 (0.991-1.985) & 0.056 & 1.196 (0.817-1.751) & 0.357 & $0.919(0.680-1.241)$ & 0.581 & $0.918(0.662-1.274)$ & 0.234 \\
\hline $6-7$ & 1 & & 1 & & 1 & & 1 & \\
\hline
\end{tabular}

$\mathrm{BMI}$, body mass index; $\mathrm{OR}$, odds ratio; $\mathrm{Cl}$, confidence interval.

cohol to excess every day, and the odds ratio was higher compared to that determined using the unadjusted model. Even when adjusted for age and BMI, lower family income and education level significantly increased the odds ratio for abdominal obesity in females with normal body weight.

\section{Association between abdominal obesity and} cardiovascular risk factors in adults with normal body weight

Fig. 1 shows the results of logistic regression analysis that was conducted to analyze the influence of abdominal obesity on cardiovascular risk factors, such as hypertension, diabetes, and dyslipidemia, in adults with a normal body weight. When unadjusted for any particular variable, abdominal obesity was associated with increased risks of prehypertension and hypertension in both males and females. However, when adjusted for both age and BMI, the increase in odds ratio was not significant.

When unadjusted for any particular variable, the risks of impaired fasting glucose and diabetes increased because of abdominal obesity in both males and females with normal body weight. In the model adjusted for age and BMI, the odds ratio for impaired fasting glucose in males was 1.844 (95\% CI, 1.271-2.674) and that for diabetes in males was 1.716 (95\% CI, 1.133-2.598). After adjustment, the significance of the increased risks of impaired fasting glucose and diabetes remained in males but not in females.

Dyslipidemia was classified as hypertriglyceridemia, hypercho- 

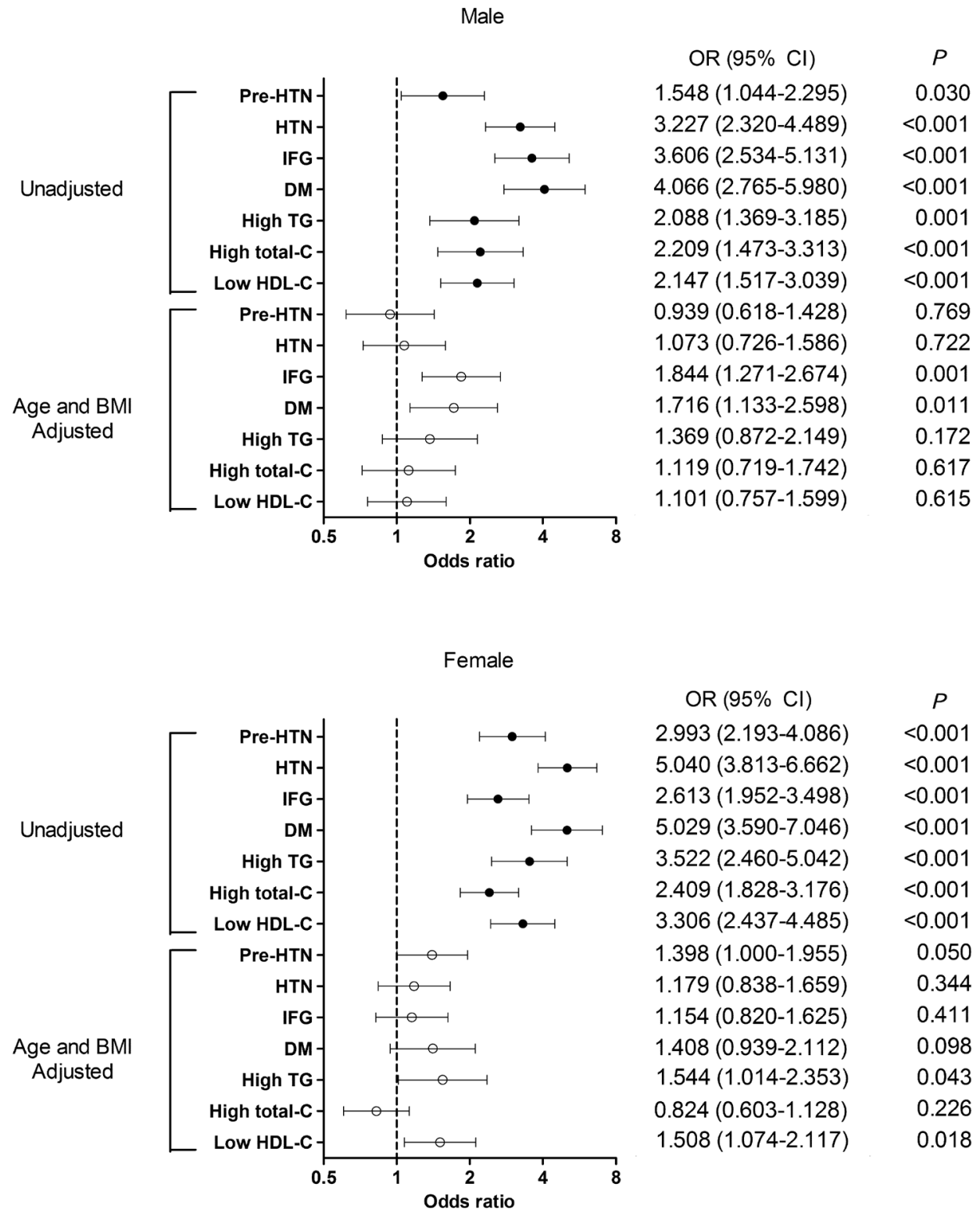

Figure 1. Unadjusted and adjusted odds ratios of cardiovascular risk factors in relation to the presence of abdominal obesity among adults with normal body mass index (BMI). OR, odds ratio; $\mathrm{Cl}$, confidence interval; $\mathrm{HTN}$, hypertension; IFG, impaired fasting glucose; DM, diabetes mellitus; TG, triglyceride; $\mathrm{C}$, cholesterol; $\mathrm{HDL}-\mathrm{C}$, high-density lipoprotein cholesterol.

lesterolemia, and hypo-HDL cholesterolemia. For both males and females, the odds ratio for hypertriglyceridemia and hypo-HDL cholesterolemia increased in the unadjusted model. However, in the model adjusted for age and BMI, the increased odds ratio due to abdominal obesity was only significant in females. The odds ratio for hypertriglyceridemia in females was 1.544 (95\% CI, 1.0142.353) and that for hypo-HDL cholesterolemia was 1.508 (95\% CI, 1.074-2.117). In males and females with normal body weight, the odds ratio for hypercholesterolemia did not increase because of abdominal obesity regardless of the analysis model.

Subjective perception of body habitus and weight loss efforts in the past year in adults with abdominal obesity despite normal body weight

Table 3 shows the subjective perception of body habitus and weight loss efforts in the past year in adults with abdominal obesity 
Table 3. Distribution of attitude and behavior toward weight in normal and abdominal obesity participants in adults with normal BMI

\begin{tabular}{|c|c|c|c|c|c|c|}
\hline \multirow{2}{*}{ Variable } & \multicolumn{3}{|c|}{ Male } & \multicolumn{3}{|c|}{ Female } \\
\hline & $W C<90 \mathrm{~cm}$ & $W C \geq 90 \mathrm{~cm}$ & $P$ & $W C<85 \mathrm{~cm}$ & $W C \geq 85 \mathrm{~cm}$ & $P$ \\
\hline Self-assessment of body weight & & & $<0.001$ & & & $<0.001$ \\
\hline Subnormal weight & $1,204(31.2)$ & $20(7.0)$ & & $774(12.3)$ & $47(9.4)$ & \\
\hline Normal weight & $2,092(55.6)$ & $159(52.7)$ & & $3,090(56.3)$ & $209(44.3)$ & \\
\hline Above normal weight & $446(13.2)$ & $99(40.3)$ & & $1,652(31.4)$ & $189(46.3)$ & \\
\hline Weight control method & & & $<0.001$ & & & 0.002 \\
\hline Lose weight & $729(21.4)$ & $80(33.5)$ & & $2,257(44.7)$ & $146(36.4)$ & \\
\hline Maintain weight & $897(22.9)$ & $66(21.7)$ & & $1,240(22.1)$ & $64(15.4)$ & \\
\hline Gain weight & $474(13.1)$ & $5(1.7)$ & & $229(3.5)$ & $15(3.1)$ & \\
\hline No method & $1,642(42.5)$ & $127(43.0)$ & & $1,789(29.7)$ & $219(45.2)$ & \\
\hline
\end{tabular}

Values are presented as number (\%).

$\mathrm{BMI}$, body mass index; $\mathrm{WC}$, waist circumference.

despite having a normal body weight. Of the adults with abdominal obesity despite having a normal body weight, $40.3 \%$ of males and $46.3 \%$ of females acknowledged their obesity, and $33.5 \%$ of males and $36.4 \%$ of females had attempted to lose weight in the past year. Fewer females in this group attempted to lose weight compared to females without abdominal obesity (44.7\%).

\section{DISCUSSION}

This study was conducted to analyze the factors that increase the risks of abdominal obesity in Korean adults with normal body weight and the relationship between abdominal obesity and cardiovascular risk factors, such as hypertension, diabetes, and dyslipidemia, based on the sixth KNHANES (2013-2015).

The prevalence of abdominal obesity in Korean adults with normal body weight was higher in females. In contrast, a previous study using the KNHANES between 1998 and 2015 reported that the prevalence of abdominal obesity was higher in males than in females. ${ }^{17}$ The mean age of the female and male groups with abdominal obesity was higher than that of the groups without abdominal obesity, and the prevalence of abdominal obesity tended to increase with age. This trend may be attributed to a combination of causes including social activities, cultural characteristics, age-related physical changes, and decreased caloric use.

When the influence of sociodemographic factors on the abdominal obesity of adults with normal body weight was assessed, the influence was not significant in males when adjusted for age and BMI. In contrast, in females, the risks of abdominal obesity increased sig- nificantly when family income and education level were lower. Previous studies also reported that obesity is influenced by socioeconomic factors in females. In a Swedish study of middle-aged females, the prevalence of metabolic syndrome decreased as education level increased; a similar finding was reported in a South Korean study of postmenopausal women. Although some studies suggested that psychosocial stress associated with low socioeconomic status activates the hypothalamus-pituitary-adrenal axis and increases the risks of metabolic diseases such as abdominal obesity, ${ }^{18}$ further studies are required to confirm this.

When adjusted for age and BMI, the risks of abdominal obesity were increased in male and female groups who engaged in harmful alcohol consumption every day. Various studies have reported a correlation between harmful alcohol consumption and obesity, ${ }^{19}$ and our results confirmed that drinking is an independent risk factor of abdominal obesity in adults with normal body weight.

Exercise has been suggested to be an important factor that decreases the prevalence of obesity. In this study, the prevalence of abdominal obesity increased significantly in males with normal body weight who performed walking exercise two or fewer times per week. However, there was no correlation between the number of days of exercise and abdominal obesity in females. Other studies using the KNHANES data reported similar findings. For instance, one study determined that there was no significant correlation between exercise and waist circumference in females aged 35 years or older; ${ }^{20}$ a similar finding was obtained in a study of post-menopausal females. ${ }^{21}$ Because the KNHANES was conducted using a selfreported questionnaire, errors may have occurred. Additionally, be- 
cause the survey was cross-sectional, difficulties in assessing a causal relationship between exercise and waist circumference arose.

Logistic regression analysis of the influence of abdominal obesity on cardiovascular risk factors (i.e., hypertension, diabetes, and dyslipidemia) in adults with normal body weight, the risks of these increased because of abdominal obesity in both males and females when the model was not adjusted for any variables. However, in the model adjusted for age and BMI, only the increased risks of impaired fasting glucose and diabetes in males and hypertriglyceridemia and hypo-HDL cholesterolemia in females were statistically significant. One possible explanation for such differences between in sex may be the differences in abdominal fat distribution and metabolic function. The ratio between the area of visceral fat and subcutaneous fat (V/S ratio) measured by $\mathrm{CT}$ is used as an index of intra-abdominal fat accumulation; this ratio is reported to be higher in males than in females. Compared to subcutaneous fat, visceral fat is more strongly correlated with blood insulin levels, blood glucose levels, and glucose bioavailability. Fujioka et al. ${ }^{22}$ reported significantly higher impaired glucose in a visceral obesity group with a $\mathrm{V} / \mathrm{S}$ ratio of $\geq 0.4$ compared to a subcutaneous obesity group with a $\mathrm{V} / \mathrm{S}$ ratio of $<0.4$. However, a recent study showed that the high spontaneous lipolysis activity of subcutaneous adipose tissue was associated with elevated triglyceride and low HDL$\mathrm{C}$ concentrations. Therefore, the sex differences in the complications of abdominal obesity in individuals with normal weight may arise because of differences in the abdominal fat distribution.

There were some limitations to this study. Only waist circumference was used to define abdominal obesity; this may not be an accurate evaluation of visceral fat. If CT is used to measure total abdominal and visceral fat, more accurate results regarding abdominal obesity can be obtained and the influence of fat distribution may be more clearly determined. Moreover, because this study was cross-sectional, we could not investigate the chronological relationship between variables and abdominal obesity so we could not identify any causal relationships. Also, dietary habits, which may also influence waist circumference, were not considered in this study and therefore require further analysis.

Using data from the sixth KNHANES (2013-2015), this study revealed that abdominal obesity increases cardiovascular risk factors in South Korean adults with normal body weight. Among adults with abdominal obesity despite having a normal body weight, fewer than half acknowledged their obesity; and fewer females with normal body weight and abdominal obesity had attempted to lose weight in the past year compared to females without abdominal obesity. These findings indicate that programs to appropriately identify and manage the risks of "abdominal obesity with normal body weight" should be developed.

\section{CONFLICTS OF INTEREST}

The authors declare no conflict of interest.

\section{AUTHOR CONTRIBUTIONS}

Study concept and design: HYK; acquisition of data: HYK; analysis and interpretation of data: HYK, JKK, and JWK; drafting of the manuscript: HYK; critical revision of the manuscript: HYK, JKK, and JWK; statistical analysis: HYK; administrative, technical, or material support: GGS, JAH, and JWK; and study supervision: JWK.

\section{REFERENCES}

1. World Health Organization, Regional Office for the Western Pacific. The Asia-Pacific perspective: redefining obesity and its treatment. Sydney: Health Communications Australia; 2000.

2. Frankenfield DC, Rowe WA, Cooney RN, Smith JS, Becker D. Limits of body mass index to detect obesity and predict body composition. Nutrition 2001;17:26-30.

3. Folsom AR, Kaye SA, Sellers TA, Hong CP, Cerhan JR, Potter $\mathrm{JD}$, et al. Body fat distribution and 5-year risk of death in older women. JAMA 1993;269:483-7.

4. Després JP, Lemieux I. Abdominal obesity and metabolic syndrome. Nature 2006;444:881-7.

5. Després JP, Lemieux I, Bergeron J, Pibarot P, Mathieu P, Larose E, et al. Abdominal obesity and the metabolic syndrome: contribution to global cardiometabolic risk. Arterioscler Thromb Vasc Biol 2008;28:1039-49.

6. Ghandehari H, Le V, Kamal-Bahl S, Bassin SL, Wong ND. Abdominal obesity and the spectrum of global cardiometabolic 
risks in US adults. Int J Obes (Lond) 2009;33:239-48.

7. Coutinho T, Goel K, Corrêa de Sá D, Carter RE, Hodge DO, Kragelund C, et al. Combining body mass index with measures of central obesity in the assessment of mortality in subjects with coronary disease: role of "normal weight central obesity". J Am Coll Cardiol 2013;61:553-60.

8. Coutinho T, Goel K, Corrêa de Sá D, Kragelund C, Kanaya AM, Zeller M, et al. Central obesity and survival in subjects with coronary artery disease: a systematic review of the literature and collaborative analysis with individual subject data. J Am Coll Cardiol 2011;57:1877-86.

9. Carr DB, Utzschneider KM, Hull RL, Kodama K, Retzlaff BM, Brunzell JD, et al. Intra-abdominal fat is a major determinant of the National Cholesterol Education Program Adult Treatment Panel III criteria for the metabolic syndrome. Diabetes 2004;53:2087-94.

10. Alberti KG, Eckel RH, Grundy SM, Zimmet PZ, Cleeman JI, Donato KA, et al. Harmonizing the metabolic syndrome: a joint interim statement of the International Diabetes Federation Task Force on Epidemiology and Prevention; National Heart, Lung, and Blood Institute; American Heart Association; World Heart Federation; International Atherosclerosis Society; and International Association for the Study of Obesity. Circulation 2009; 120:1640-5.

11. Lee S, Park HS, Kim SM, Kwon HS, Kim DY, Kim DJ, et al. Cut-off points of waist circumference for defining abdominal obesity in the Korean population. Korean J Obes 2006;15:1-9.

12. Smith SC Jr, Haslam D. Abdominal obesity, waist circumference and cardio-metabolic risk: awareness among primary care physicians, the general population and patients at risk. The Shape of the Nations survey. Curr Med Res Opin 2007;23:
$29-47$.

13. Zhang P, Wang R, Gao C, Jiang L, Lv X, Song Y, et al. Prevalence of central obesity among adults with normal BMI and its association with metabolic diseases in Northeast China. PLoS One 2016;11:e0160402.

14. Kim MK, Han K, Kwon HS, Song KH, Yim HW, Lee WC, et al. Normal weight obesity in Korean adults. Clin Endocrinol (Oxf) 2014;80:214-20.

15. Han JH, Kim SM. Relationship between percent body fat and cardiovascular risk factors for normal weight adults. J Korean Acad Fam Med 2006;27:352-7.

16. Shin SW, Park SK, Jung MK, Ji HS. Association of regional fat measured by DEXA and cardiovascular risk factors in normal BMI adult. Korean J Fam Pract 2015;5(Suppl 3):S851-5.

17. Oh SW. Recent epidemiological changes in Korean obesity. Korean J Helicobacter Up Gastrointest Res 2017;17:62-5.

18. Björntorp P. Behavior and metabolic disease. Int J Behav Med 1996;3:285-302.

19. Traversy G, Chaput JP. Alcohol consumption and obesity: an update. Curr Obes Rep 2015;4:122-30.

20. Paek KW, Hong YM. Health behavior factors affecting waist circumference as an indicator of abdominal obesity. J Prev Med Public Health 2006;39:59-66.

21. Kang J, Lee YJ, Choi J, Cho H, Lee E. The factors associated with abdominal obesity in Korean middle-aged postmenopausal women: Korean national health and nutrition examination survey 2010-2012. Korean J Fam Pract 2016;6:199-204.

22. Fujioka S, Matsuzawa Y, Tokunaga K, Tarui S. Contribution of intra-abdominal fat accumulation to the impairment of glucose and lipid metabolism in human obesity. Metabolism 1987;36: 54-9. 